\title{
Literature Review of Cloud Computing in Education Sector: A survey with respect to Qatar
}

\author{
Atif Ishaq \\ Szabist \\ MS(Information Technology) \\ Dubai,UAE
}

\author{
M.N. Brohi, PhD \\ Szabist \\ Head of Campus \\ Dubai,UAE
}

\begin{abstract}
In this paper we discussed on Cloud technology is implementing everywhere so cloud technology is been implanted in education sector. Different authors have different views cloud technology in education sector. Cloud what does meaning for education sector. The key benefits of cloud computing in education. In the end of this paper survey was conducted in different educational school, academies and colleges where already implemented and some are under process. A mostly organization wants a framework/model to keep their data more secure over cloud.
\end{abstract}

\section{Keywords}

Cloud Computing ,Education ,Benefits, Cost, survey.

\section{INTRODUCTION}

Computing is transmuted to a mode commoditized and mannerly delivered alike to tradition such as water and electricity in this kind of models services access depends upon the used requirements without respect to where facilities have been hosted and how they will be delivered. Many computing prototypes have promised us deliver this utility computing vision and these include Grid, cluster computing, and recently cloud computing [1].In the second part of the paper we deeply more focuses on different authors have different views on cloud with education sector. They talked about the benefits. In the last part conducted survey on the basis of literature.

\section{CLOUD COMPUTING - WHAT IS IT AND WHAT DOES IT MEAN FOR EDUCATION?}

The opportune distribution of Education accumulation of articles on registering and training, The Tower and the Cloud conveys consideration regarding numerous ranges where the cloud may encroach on instruction. Given the size of that book and the extent of this article, it is illogical to practice every one of the worries here. I will guide regard for a couple of the papers though. The Gathering Cloud: Is this the end of the center? Is a magnificent general beginning stage? Yanosky's 'From Users to choosers: The cloud and the changing state of big business power' and Goldstein's 'The Tower, the Cloud, and the IT pioneer and workforce' both location the effect distributed computing will probably have on IT administration and procedure with HE establishments. [2].

\section{FROM TRADITIONAL E-LEARNING NETWORK TO CLOUD EDUCATION}

E-learning is an Web based learning procedure, utilizing Internet innovation to plan, execute, select, oversee, bolster and develop realizing, which won't supplant conventional training systems, yet will significantly enhance the

Proficiency of instruction. As e-learning has a ton of favorable circumstances like adaptability, differing qualities, estimation, opening et cetera, it will end up being an essential route for learning in the new century as in Fig Architecture of simplified Learning System.

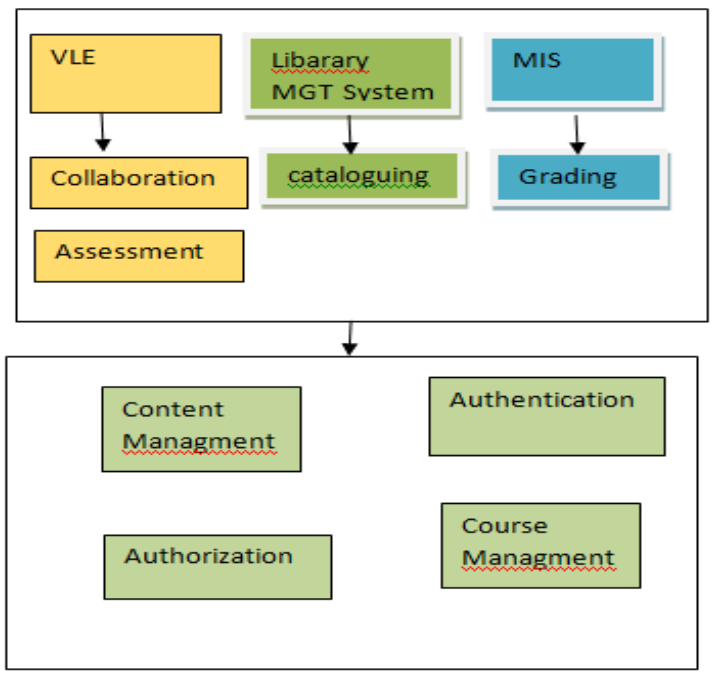

Fig 1: Traditional e-learning Architecture

Mendez illustrates that in traditional online learning mode, framework development and upkeep are situated inside the instructive organizations or endeavors, which prompted a great deal of issues, for example, noteworthy speculation required however without capital additions for them, which prompts an absence of improvement potential. Conversely, cloud-based e-learning model presents scale effectiveness system, i.e. development of e-learning framework is endowed to distributed computing suppliers, which can make suppliers and clients to accomplish a win-win circumstance. The cloudbased environment bolsters the formation of new era of elearning frameworks, ready to keep running on an extensive variety of equipment gadgets, while putting away information inside the cloud. [3] 


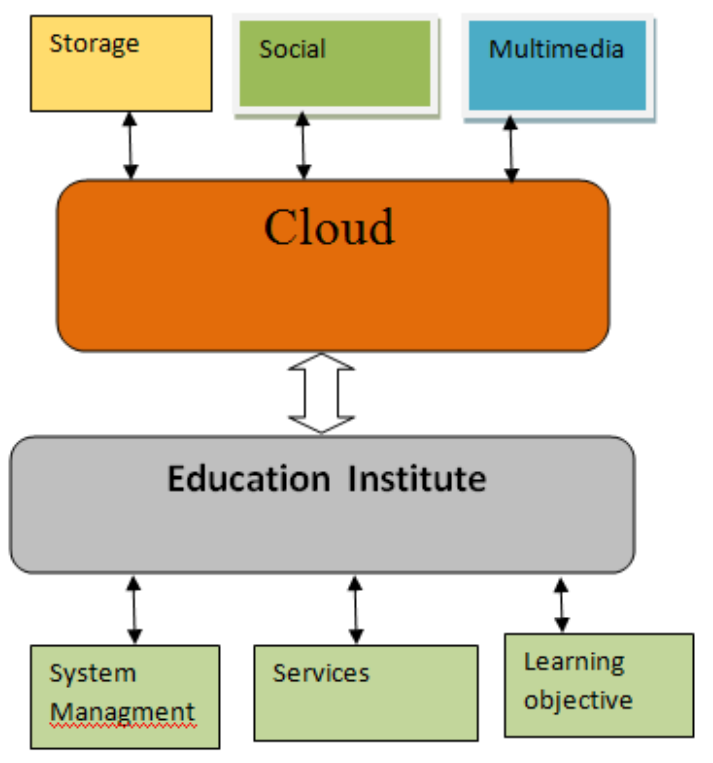

Fig 2: Cloud Computing E-learning Architecture

\section{KEY BENEFITS OF CLOUD BASED E-LEARNING}

There are numerous advantages when the e-learning is implemented with the cloud computing technology, they are:

\subsection{Cost}

E-Learning users need not have high end configured computers to run the e-learning applications. They can run the applications from cloud through their PC, mobile phones, tablet PC having minimum configuration with internet connectivity. Since the data is created and accessed in the cloud [4]

\subsection{Improved performance}

Since the cloud based e-learning applications have most of the applications and processes in cloud, client machines do not create problems on performance when they are working.

\subsection{Instant software updates}

Since the cloud based application for e-learning runs with the cloud power, the software's are automatically updated in cloud source. So, always e-learners get updates instantly.

\subsection{Benefits for students}

Students get more advantages through cloud based e-learning. They can take online courses, attend the online exams, get feedback about the courses from instructors, and send their projects and assignments through online to their teachers. [5]

\subsection{Benefits for teachers}

Instructors additionally get various advantages over cloud based e-learning. Instructors have the capacity to get ready online tests for understudies, arrangement and make better substance assets for understudies through substance administration, evaluate the tests, homework, tasks taken by understudies, send the input and correspond with understudies through online discussions. [6]

\section{CLOUD Education for the Universities}

The college's needs to take after every one of the standards and regulation of the state and nation for building up a cloud for training the same number of nations are extremely strict in cross more extensive exchange of data. Once the college sets up where their information will dwell and gives the measure of information security an understanding called SLA (Service Level Agreement) can be made with the cloud administration supplier. The SLA is a record which can guarantee instructive cloud clients in regards to the administrations gave by the cloud. It tries to distinguish the clients require and streamlines complex issues and makes a relationship between the client and the administration supplier. It determines the protection, consistency and trustworthiness. [6] Privacy is one of the imperative elements which must be taken nurture distributed computing, as the administration supplier may require some individual data which is identified with the There are numerous arrangements that can guarantee the security and insurance of delicate information in the cloud. [7] [8], [9], [10]

These are;
1) Mask or de-identify of the data
2) Firewalls
3) Encryption and decryption
4) Authorization identity management.

\section{CLOUD IN THE EDUCATION}

The capability of distributed computing for enhancing effectiveness, expense and comfort for the instructive segment is being perceived by a number US instructive foundations. The University Of California (UC) at Berkeley, for instance, observed distributed computing to be appealing to use in one of their courses which was engaged only on creating and conveying SaaS applications. For some colleges, the accessibility of a great figuring force through distributed computing for examination intentions was welcome. Specialists at the Medical College of Wisconsin Biotechnology and Bioengineering Center in Milwaukee are making protein inquire about (an exceptionally costly undertaking) more open to researchers around the world, on account of leasing preparing time on Google's effective cloudbased servers.[11]

\section{LEARNING PERFORMERS IN CLOUD COMPUTING [12]}

A Learning Actor is any entity involved in the learning process like management, students, instructors, lab staff etc. There are five types of resources that can be provisioned and a Learning Actor can consume over the Internet [13].

1) Base assets including processing force, stockpiling, and machine provisioning.

2) Software assets including middleware (cloud-driven working frameworks, application servers, databases) and advancement assets (improvement, testing apparatuses, and organization instruments).

3) Application assets. Instructive Software applications are conveyed through Software as a Service (SaaS) model or mashups of worth included applications.

4) Learning procedures. Applications uncovered as utilities or errands. Learning procedure sharing is the learning-driven application outsourcing that backings provisioning, reuse and creation.

5) Learning Objects. 


\section{THE APPLICATION OF CLOUD COMPUTING IN EDUCATION INFORMATIZATION[14]}

\subsection{Learning Under The Network} Environment

Current training speculations feel that the understudies who ought to be the principle group of educating are not passive but rather activity. It will be a propensity of cutting edge instructing systems. In the customary showing environment, individuals have been neglected to locate a perfect of individualized learning methodology. Times in the cloud, the learner as per the kind of cloud administrations, free decision learning substance and learning routines.

\subsection{Application Of SAAS In Education Information}

Software as a Service (SAAS) is a Cutting edge training hypotheses feel that the understudies who ought to be the primary assemblage of instructing are not inactive but rather activity. It will be a propensity of current educating routines. In the customary showing environment, individuals have been neglected to locate a perfect of individualized learning methodology. Times in the cloud, the learner as indicated by the kind of cloud administrations, free decision learning substance and learning techniques.

\subsection{Under The Patterns Of Cloud Computing Environment, The} Construction Of Net-Teaching Database

Distributed computing made a present day system of showing asset library building where numerous can gain from. Later on, distributed computing environment, how to assemble internet showing asset library we need to consider the issue has ended up. Library building is a long haul venture, there must be long haul arranging. To empower sound and maintainable improvement. Instructing Resources to bolster showing and research ought to be a definitive goal, Training and Learning as a Service (ELaaS) system.

\section{SURVEY}

Survey was conducted in different schools, Colleges and Academies. In some educational firms they already implemented the cloud technology and some of them are under process.

\subsection{Is Your Organization Using Cloud Technology?}

In Qatar mostly educational firms already implemented cloud technology where others are in process. More than 55\% educations firms are implemented some are on high level.

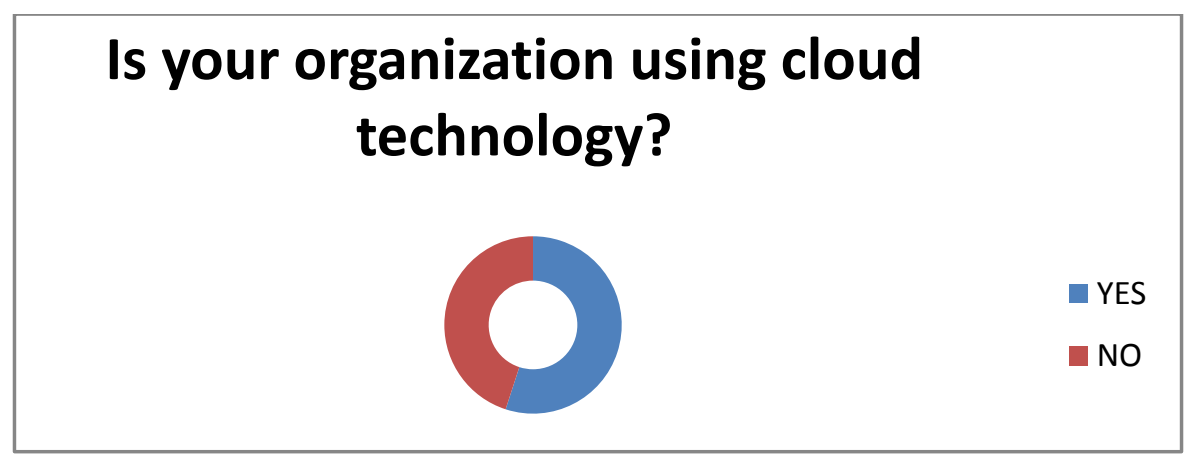

Fig 3: Organization using cloud technology

\subsection{At What Stage Is Your Organization}

With Regards To Cloud Computing?

Mostly institutes the already implemented the cloud technology in the school but still they have some security issues which they are facing nowadays.

\section{At what stage is your organisation with regards to cloud computing?}

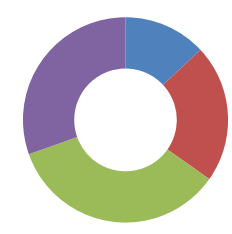

$$
\begin{aligned}
& \text { Not involved } \\
& \text { discussing } \\
& \text { Trial } \\
& \text { implemented }
\end{aligned}
$$

Fig 4: Organization with regards to cloud computing 


\subsection{What Does Your Organization View As}

The Most Important Benefits Of The

Cloud?

Mostly institute which they implemented or some which they are under process of implementation. They want cloud technology because of easy access (56\%) and paperless $(35 \%)$.

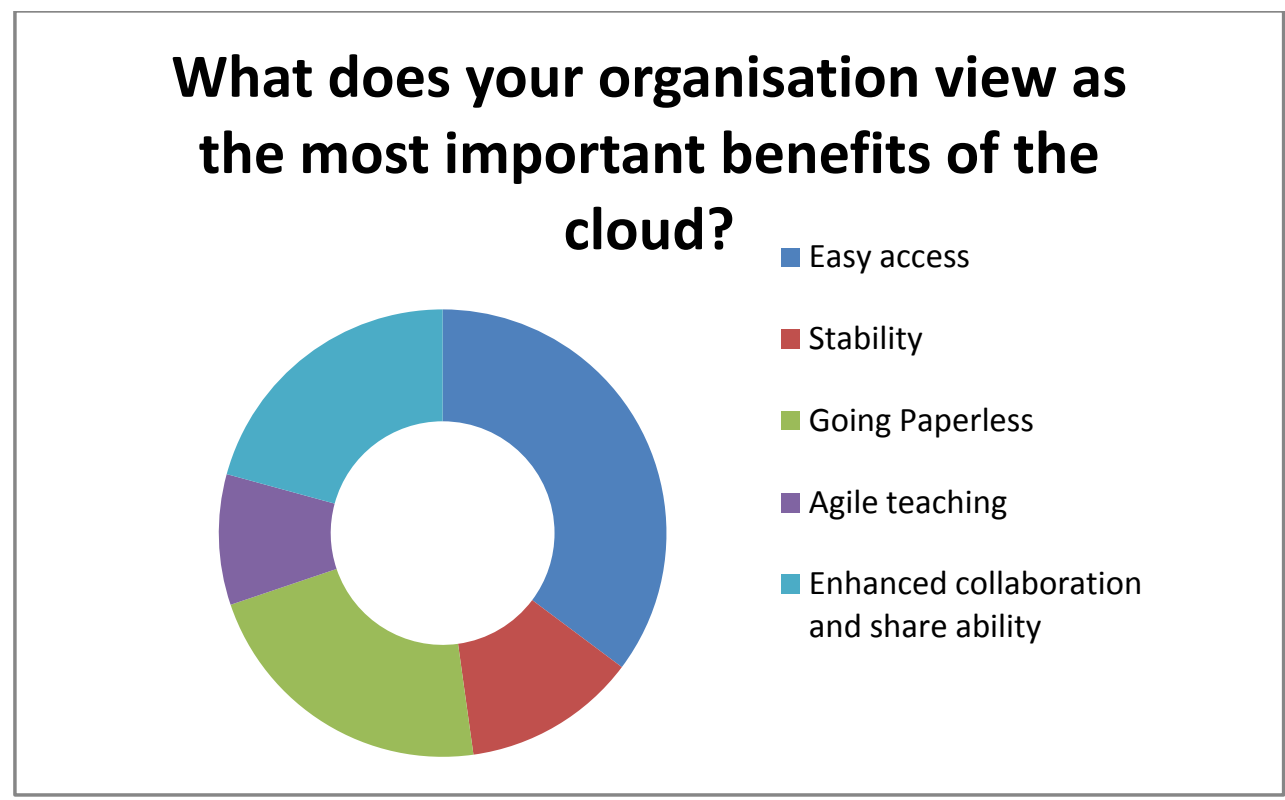

Fig 5: Important benefits of the cloud

\subsection{What Are The Greatest Barriers For}

Adoption Of The Cloud In Your

Organization?

When any institute or organization implement any kind of technology they have barriers

\section{What are the greatest barriers for adoption of the cloud in your organisation?}

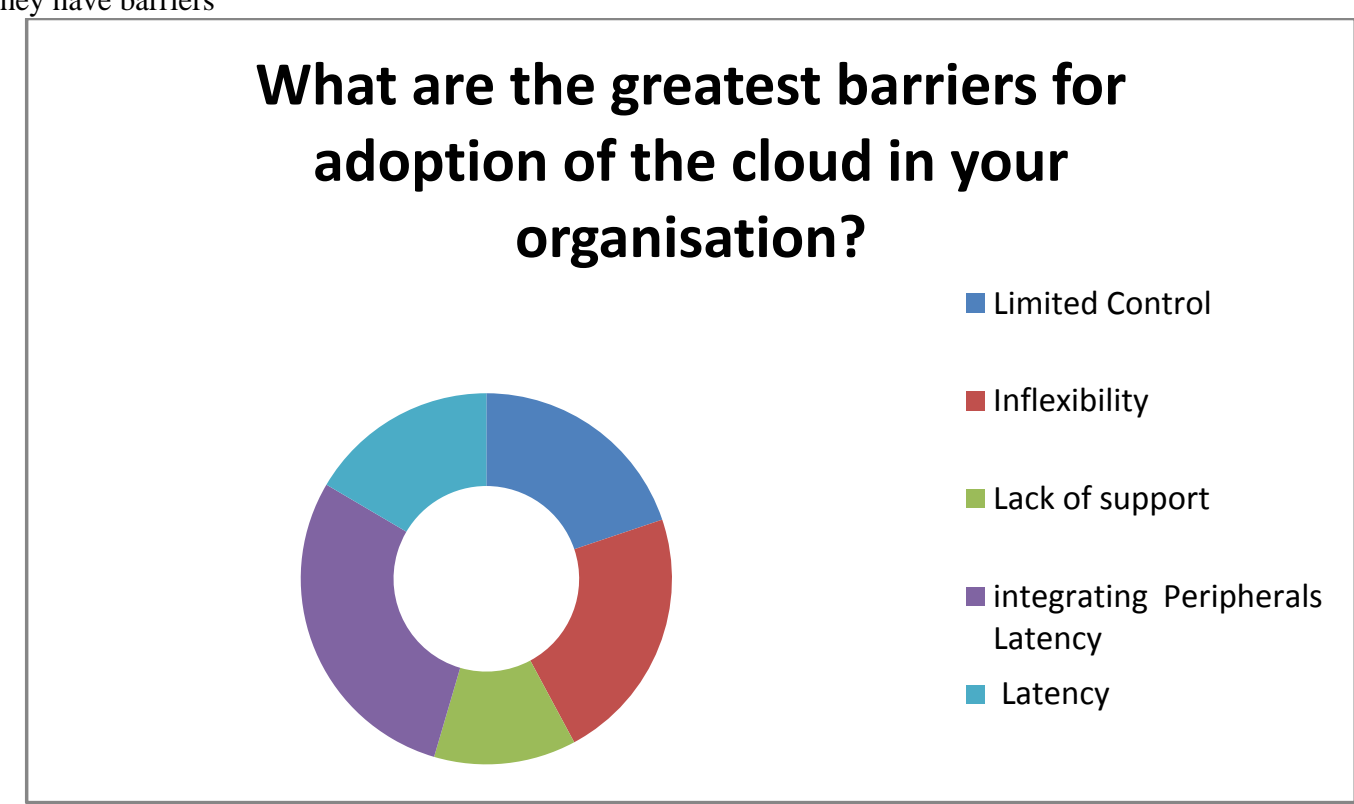

While implementation .In this case mostly said that they problem integration of peripheral devices or wireless connectivity.

Fig 6: Barriers for adoption of the cloud

\subsection{Is There Any Security Standard(S)}

Being Implemented?

$65 \%$ they implemented security standards because in cloud security and privacy issues are major concern. 


\section{Is there any security standard(s) being implemented?}

9.6 Is there any SLA (service level agreement) before implementation of cloud technology?

SLA (service level agreement) is one of the most important parts of cloud implementation.

\section{Is there any SLA (service level agreement) before implemtation of...}

Fig 8: Service Level Agreement

\subsection{How To Recover From Disaster}

\section{Recovery In Cloud?}

Data recovery is one of the main aspects of cloud technology because security is still one of the main issues over cloud. So there have different ways to overcome from disaster recovery .Mostly are using Backup (35\%).

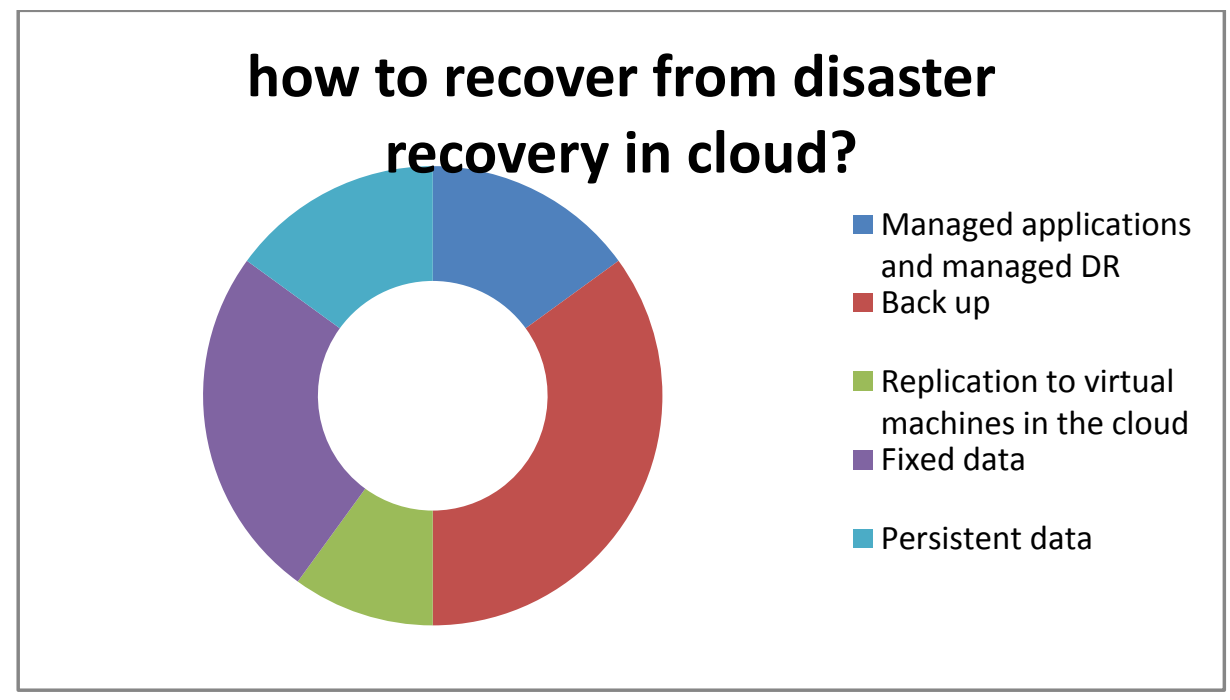

Fig 9: Disaster Recovery 


\title{
9.8 What are the Benfits of cloud in the education sector?
}

There are different benefits of cloud technology in education sector. Every organization has different point of views. Mostly they implemented because of Learning management system $(35 \%)$ and student information system $(30 \%$.)

\section{What are the Benfits of cloud in the education sector?}

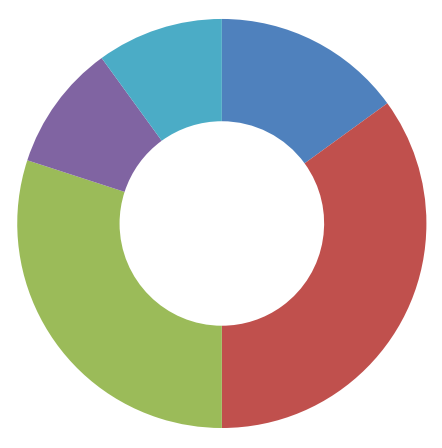

\author{
Productivity \\ - Learning mangment \\ system \\ Student information \\ system \\ - Help desk
}

Event schelding

Fig 10: Benefits of Cloud

\section{CONCLUSION}

Cloud computing technology is day by day enhancing but on the other hand there are many things to need be more secure. In cloud technology big issue is security .According to survey mostly institution want more secure their data of the students to be safe over cloud but for now there is no such framework is developed. In this case should be proper framework to be proposing to make more security and privacy. Many ways to make secure not only through cloud technology also using different standards like ITIL

\section{FUTURE WORK}

As we know every technology is updating day by day so cloud technology and e-learning, So for keeping secure data on the cloud we need to proposed a framework for the futurelearning enhancing very quickly and almost all schools are using so for e-learning should use some other technologies keep data safe locally or on the cloud.

\section{REFERENCES}

[1] Buyya, Rajkumar, et al. "Cloud computing and emerging IT platforms: Vision, hype, and reality for delivering computing as the 5th utility." Future Generation computer systems 25.6 (2009): 599-616.

[2] Powell, John. "Cloud computing-what is it and what does it mean for education." revolution. jiscinvolve. org/wp/files/2009/07/Clouds-johnpowell. pdf(2009).

[3] Masud, Md Anwar Hossain, and Xiaodi Huang. "An elearning system architecture based on cloud computing." system 10.11 (2012).

[4] Kondo, Derrick, et al. "Cost-benefit analysis of cloud computing versus desktop grids." Parallel \& Distributed Processing, 2009. IPDPS 2009. IEEE International Symposium on. IEEE, 2009.
[5] Maskare, Poonam R., and Sarika R. Sulke. "Review Paper on E-learning Using Cloud Computing." (2014).

[6] Riahi, Ghazal. "E-learning Systems Based on Cloud Computing: A Review."Procedia Computer Science 62 (2015): 352-359.

[7] B. R. Kandukuri, V. R. Paturi, and A. Rakshit, "Cloud Security," in proceedings of the 2009 IEEE International Conference on Services Computing, Washington, DC, USA, 2009, IEEE Computer Society, pp. 517-520

[8] Mathew, Saju. "Implementation of cloud computing in education-A Revolution."education 1.5 (2012): 6. J. L. Nicholson. Cloud Computing: Top Issues for Higher Education. [Online].

[9] R. N. Katz, The Tower and the Cloud: Higher Education in the age of cloud computing, 2008

[10] R. Katz, P. Goldstein, and R. Yanosky, "Cloud Computing in Higher Education," Educause. [Online]. 2010.

[11] Sultan, Nabil. "Cloud computing for education: A new dawn?." International Journal of Information Management 30.2 (2010): 109-116.

[12] Kalagiakos, Panagiotis, and Panagiotis Karampelas. "Cloud computing learning." Application of Information and Communication Technologies (AICT), 2011 5th International Conference on. IEEE, 2011.

[13] L. Zhang and Q. Zhou, "CCOA: Cloud Computing Open Architecture", IEEE International Conference on Web Services 2009, IEEE Computer Society, pp. 607-616.

[14] Wang, Bo, and HongYu Xing. "The application of cloud computing in education informatization." Computer Science and Service System (CSSS), 2011 International Conference on. IEEE, 2011. 